\title{
Solar activity affects the occurrence of synoptic types over Europe
}

\author{
R. Huth ${ }^{1}$, J. Kyselý ${ }^{1}$, J. Bochníček ${ }^{2}$, and P. Hejda ${ }^{2}$ \\ ${ }^{1}$ Institute of Atmospheric Physics, Boční II 1401, 14131 Praha 4, Czech Republic \\ ${ }^{2}$ Institute of Geophysics, Boční II 1401, 14131 Praha 4, Czech Republic
}

Received: 14 December 2007 - Revised: 27 May 2008 - Accepted: 23 June 2008 - Published: 23 July 2008

\begin{abstract}
The solar effects on tropospheric circulation over Europe are investigated by counting the occurrence of HessBrezowsky synoptic types under various levels of solar activity. Solar minima are accompanied by a lower incidence of westerly types and a higher incidence of easterly and northerly types. The types with a northeast and northwest flow are most frequent under a moderate solar activity. There is a weak tendency towards the anticyclonic (cyclonic) types to be less (more) frequent under moderate solar activity. Our results are in accord with previous studies, indicating a strengthened zonal flow in solar maxima and changes in the modes of low-frequency circulation variability. The results point to the fact that the effects of solar activity are not linear.
\end{abstract}

Keywords. Meteorology and atmospheric dynamics (General circulation; General or miscellaneous)

\section{Introduction}

The body of evidence that solar activity, and in particular, its 11-year cycle, affects tropospheric circulation, is growing. The circulation features so far examined in this respect include the latitudinal position of storm tracks (Brown and John, 1979; Tinsley, 1988), the position of major action centres (Christoforou and Hameed, 1997), blocking activity (Barriopedro et al., 2008), Northern and Southern annular modes (Ruzmaikin and Feynman, 2002; Ogi et al., 2003, 2004; Kuroda and Kodera, 2005; Huth et al., 2007), and position, intensity, and spatial extent of the North Atlantic Oscillation (Boberg and Lundstedt, 2002; Kodera, 2002, 2003) as well as other modes of atmospheric low-frequency variability (Huth et al., 2006). The composite analysis revealed an enhanced zonality of tropospheric circulation in the mid lati-

Correspondence to: R. Huth

(huth@ufa.cas.cz) tudes under high solar activity (Bochníček and Hejda, 2002, 2005).

The majority of the above studies were concerned with the characteristics describing the atmospheric circulation on large spatial scales and in the low frequency domain. It appears sensible to extend the research into the solar effects on the tropospheric circulation by analyzing shorter temporal and smaller spatial scales. As a convenient tool for characterizing tropospheric circulation on daily and subcontinental scales, classifications of circulation patterns (circulation types) may be used. In the classifications, each day is usually classified with one circulation type (see, e.g. Huth, 1996). Counting the frequencies of the types separately under different levels of solar activity may provide a measure of solar effects independent of the previous analyses, and hence support (or alternatively cast doubts on) their results.

\section{Data and methods}

The analysis deals with extended winter (December to March). The period covered extends from December 1949 to March 2003, altogether amounting to 216 months.

Solar activity is characterized by monthly means of the $10.7 \mathrm{~cm}$ solar radio flux (F10.7). The data were taken from the World Data Center A, Colorado, US. There is another widely used measure of the solar activity, the solar spots number (also called Wolf number); its main advantage is that its data series reach far into the past. For a discussion of the properties of the two measures and their relative merits, refer e.g. to Benestad (2002). Our previous work (e.g. Huth et al., 2006) based on the stratification procedure (see below) indicates that the results are insensitive to the definition of the solar activity. The data are stratified according to the solar activity level into three groups, corresponding to a low, moderate, and high activity. The low and high activity are alternatively referred to as solar minima and maxima,

Published by Copernicus Publications on behalf of the European Geosciences Union. 

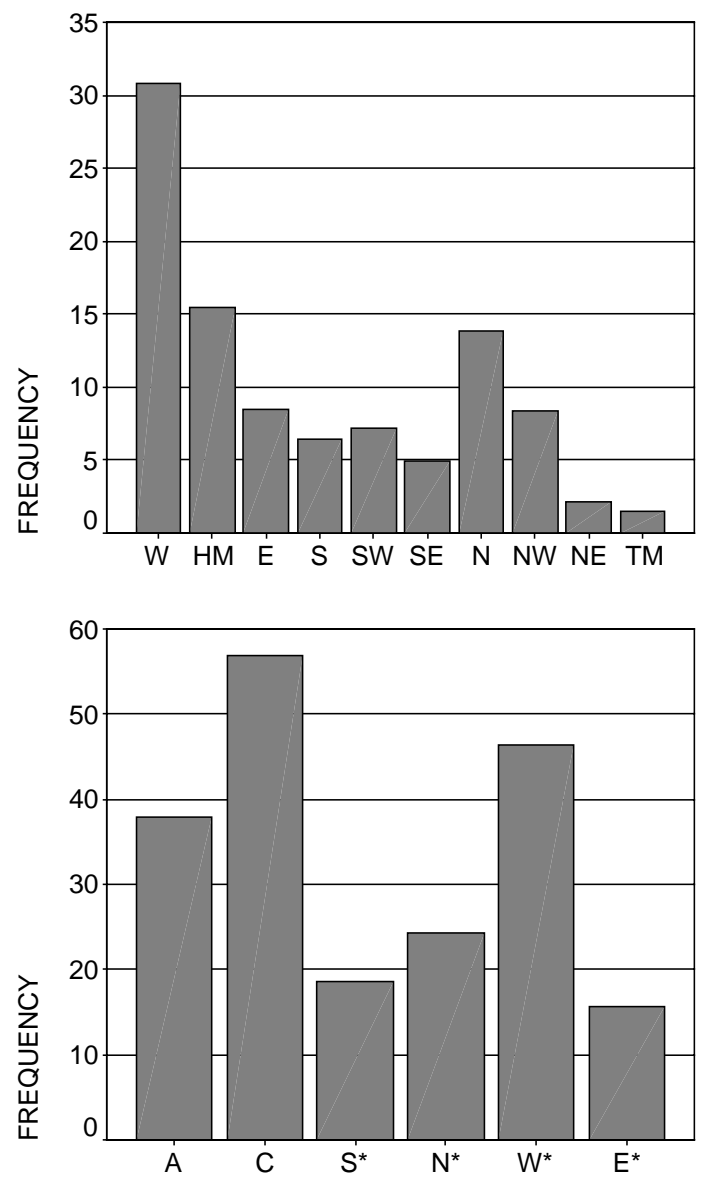

Fig. 1. Long-term mean relative frequency (in per cent) of the major types (top) and supertypes (bottom). For the notation of major types and supertypes, see Table 2.

respectively. Three stratifications, differing in the extremity of the definition of solar minima and maxima, are employed, similarly to Huth et al. (2006): 1 . The data are divided by the terciles into the equal-sized thirds, the lower, middle, and upper thirds corresponding in turn to a low, moderate, and high solar activity. 2 . The data are divided by the lower and upper quartiles into three groups comprising the lower $25 \%$ of months (low solar activity), the central half of months (moderate activity), and the upper $25 \%$ of months (high activity). 3. The solar minima and maxima are defined subjectively as the peaks and valleys, respectively, in a plot of the F10.7 time series, the rising and decreasing parts of the series being attributed to the moderate activity. The stratifications are in turn referred to as "thirds", "quarters", and " $\min / \mathrm{max}$ " in the further text. For an illustration of the stratifications, see Fig. 1 in Huth et al. (2006). Table 1 displays the number of months classified with low, moderate, and high solar activity in individual stratifications.

As a classification of circulation (synoptic) patterns, the Hess and Brezowsky (H\&B) catalogue is used (e.g. Gersten-
Table 1. Numbers of months classified with low, moderate, and high solar activity in individual stratifications ("thirds", "min/max", "quarters").

\begin{tabular}{lccc}
\hline & low & average & high \\
\hline thirds & 72 & 72 & 72 \\
min/max & 64 & 84 & 68 \\
quarters & 54 & 108 & 54 \\
\hline
\end{tabular}

garbe et al., 1999). Indeed, there are many different catalogues available over Europe, both subjectively and objectively defined. There are three major reasons for choosing $H \& B$. First, it has been extensively and successfully applied in many meteorological and climatological studies and is suitable for characterizing atmospheric circulation and weather conditions in a wide central European area. Second, $\mathrm{H} \& \mathrm{~B}$ circulation types are intuitively defined by a few basic characteristics of atmospheric circulation and can be discussed without a detailed description of the classification procedures and the types themselves. Third, the time series of the H\&B catalogue goes back to 1881 , which makes it possible to extend the present work by several more solar cycles in a future study. The H\&B catalogue consists of 29 circulation types and one group of undetermined patterns; for their list and brief description see Table 2 . The types are characterized primarily by the position of governing pressure formations (cyclones and anticyclones), and consequently by the direction and strength of the pressure gradient and air flow. The duration of each event (defined as a sequence of days classified with one type, preceded and followed by another type) is kept at three days at minimum (except for the undetermined type). The H\&B types are grouped according to their general circulation character into ten major types (Grosswetterlagen, GWL, in their original description in German). We grouped the types additionally according to their prevailing cyclonicity/anticyclonicity over central Europe and according to the dominant flow direction into six overlapping "supertypes" (Table 2). The two H\&B types with undetermined cyclonicity over central Europe (HB, TB) are not assigned to any (anti)cyclonic supertype. The directional supertypes are composed of the major types with a flow from the four main directions: westerly supertype $\left(\mathrm{W}^{*}\right)$ is composed of the northwest (NW), west (W), and southwest (SW) major types, etc. To clearly distinguish between the major types and supertypes, the latter are denoted by an asterisk.

The analysis is carried out on a monthly basis, i.e. for each class of solar activity in each stratification, we calculate the mean frequency of each H\&B type, major type, and supertype. In each class, we test the null hypothesis that the frequency of a particular circulation type (regardless of whether it is a $H \& B$ type, major type, or supertype) is equal to its 
Table 2. List of the H\&B types with their brief description and their attribution into the major types and supertypes.

\begin{tabular}{|c|c|c|c|c|}
\hline type & $\begin{array}{l}\text { major } \\
\text { type }\end{array}$ & $\begin{array}{c}\text { (anti-) cyclonic } \\
\text { supertypes }\end{array}$ & $\begin{array}{l}\text { directional } \\
\text { supertypes }\end{array}$ & brief description \\
\hline WZ & W & $\mathrm{C}$ & $\mathrm{W}^{*}$ & west cyclonic \\
\hline WA & $\mathrm{W}$ & A & $\mathrm{W}^{*}$ & west anticyclonic \\
\hline WW & $\mathrm{W}$ & $\mathrm{C}$ & $\mathrm{W}^{*}$ & west angular \\
\hline WS & $\mathrm{W}$ & $\mathrm{C}$ & $\mathrm{W}^{*}$ & west with southern cylone track \\
\hline HM & $\mathrm{HM}$ & A & - & central European high \\
\hline $\mathrm{BM}$ & $\mathrm{HM}$ & A & - & central European ridge \\
\hline TM & TM & $\mathrm{C}$ & - & central European low \\
\hline SWA & SW & A & $\mathrm{S}^{*}, \mathrm{~W}^{*}$ & southwest anticyclonic \\
\hline SWZ & SW & $\mathrm{C}$ & $\mathrm{S}^{*}, \mathrm{~W}^{*}$ & southwest cyclonic \\
\hline NWA & NW & A & $\mathrm{W}^{*}, \mathrm{~N}^{*}$ & northwest anticyclonic \\
\hline NWZ & NW & $\mathrm{C}$ & $\mathrm{W}^{*}, \mathrm{~N}^{*}$ & northwest cyclonic \\
\hline NA & $\mathrm{N}$ & A & $\mathrm{N}^{*}$ & north anticyclonic \\
\hline NZ & $\mathrm{N}$ & $\mathrm{C}$ & $\mathrm{N}^{*}$ & north cyclonic \\
\hline HNA & $\mathrm{N}$ & A & $\mathrm{N}^{*}$ & north anticyclonic, Icelandic high \\
\hline $\mathrm{HNZ}$ & $\mathrm{N}$ & $\mathrm{C}$ & $\mathrm{N}^{*}$ & north cyclonic, Icelandic high \\
\hline $\mathrm{HB}$ & $\mathrm{N}$ & - & $\mathrm{N}^{*}$ & high over the British Isles \\
\hline TRM & $\mathrm{N}$ & $\mathrm{C}$ & $\mathrm{N}^{*}$ & central European trough \\
\hline NEA & $\mathrm{NE}$ & A & $\mathrm{N}^{*}, \mathrm{E}^{*}$ & northeast anticyclonic \\
\hline NEZ & $\mathrm{NE}$ & $\mathrm{C}$ & $\mathrm{N}^{*}, \mathrm{E}^{*}$ & northeast cyclonic \\
\hline HFA & $\mathrm{E}$ & A & $\mathrm{E}^{*}$ & Fennoscandian high anticyclonic \\
\hline HNFA & $\mathrm{E}$ & A & $\mathrm{E}^{*}$ & Norwegian Sea/Fennoscandian high anticyclonic \\
\hline HFZ & $\mathrm{E}$ & $\mathrm{C}$ & $\mathrm{E}^{*}$ & Fennoscandian high cyclonic \\
\hline HNFZ & $\mathrm{E}$ & $\mathrm{C}$ & $\mathrm{E}^{*}$ & Norwegian Sea/Fennoscandian high cyclonic \\
\hline SEA & SE & A & $E^{*}, S^{*}$ & southeast anticyclonic \\
\hline SEZ & SE & $\mathrm{C}$ & $E^{*}, S^{*}$ & southeast cyclonic \\
\hline SA & $\mathrm{S}$ & A & $\mathrm{S}^{*}$ & south anticyclonic \\
\hline SZ & S & $\mathrm{C}$ & $\mathrm{S}^{*}$ & south cyclonic \\
\hline TB & S & - & $\mathrm{S}^{*}$ & low over the British Isles \\
\hline TRW & S & $\mathrm{C}$ & $\mathrm{S}^{*}$ & trough over western Europe \\
\hline $\mathrm{U}$ & - & - & - & undetermined \\
\hline
\end{tabular}

long-term mean (climatological) frequency. The statistical significance is determined by a block resampling procedure, in which the real series of events of H\&B types in DecemberMarch over 1949-2003 is randomly reshuffled $10^{4}$ times, taking each occurrence of any type (lasting at least 3 days) as a block. The null hypothesis is tested against the twosided alternative and is thus rejected, for example, at the $95 \%$ level, if the observed ratio of the frequency in the solar activity class and the climatological frequency is lower (higher) than the 250th (9750th) value of the ratio among the reshuffled series. The rejection of the null hypothesis means that the frequency of a particular circulation type is significantly different in the given solar activity class than in the whole data.

The sample sizes are low for many individual H\&B types, for which reason the statistical significance is difficult to prove. Therefore, we limit ourselves in this paper to analyzing and discussing the major types and supertypes.

\section{Results}

The long-term mean frequency of the major types and supertypes is displayed in Fig. 1. As is well known, it is the westerly types (W) that are most frequent in winter. On the other hand, the south-east (SE) and north-east (NE) types, and the central European low (TM), are among those least frequent. When looking at the supertypes, one can notice the prevalence of the cyclonic situations (C) over the anticyclonic ones (A). Among the directionally-defined supertypes, the westerly one $\left(\mathrm{W}^{*}\right)$ is again the most frequent, the other three (northerly, easterly, and southerly; $N^{*}, E^{*}, S^{*}$ ) occurring approximately with the same frequency.

Results are summarized in Fig. 2. Its left (right) panels display results for major types (supertypes). The top, middle, and bottom row corresponds in turn to the thirds, $\min / \mathrm{max}$, and quarters stratification. The extremity of the definition of solar minima and maxima thus increases from the top to bottom. Each graph displays the ratio of the frequency in 

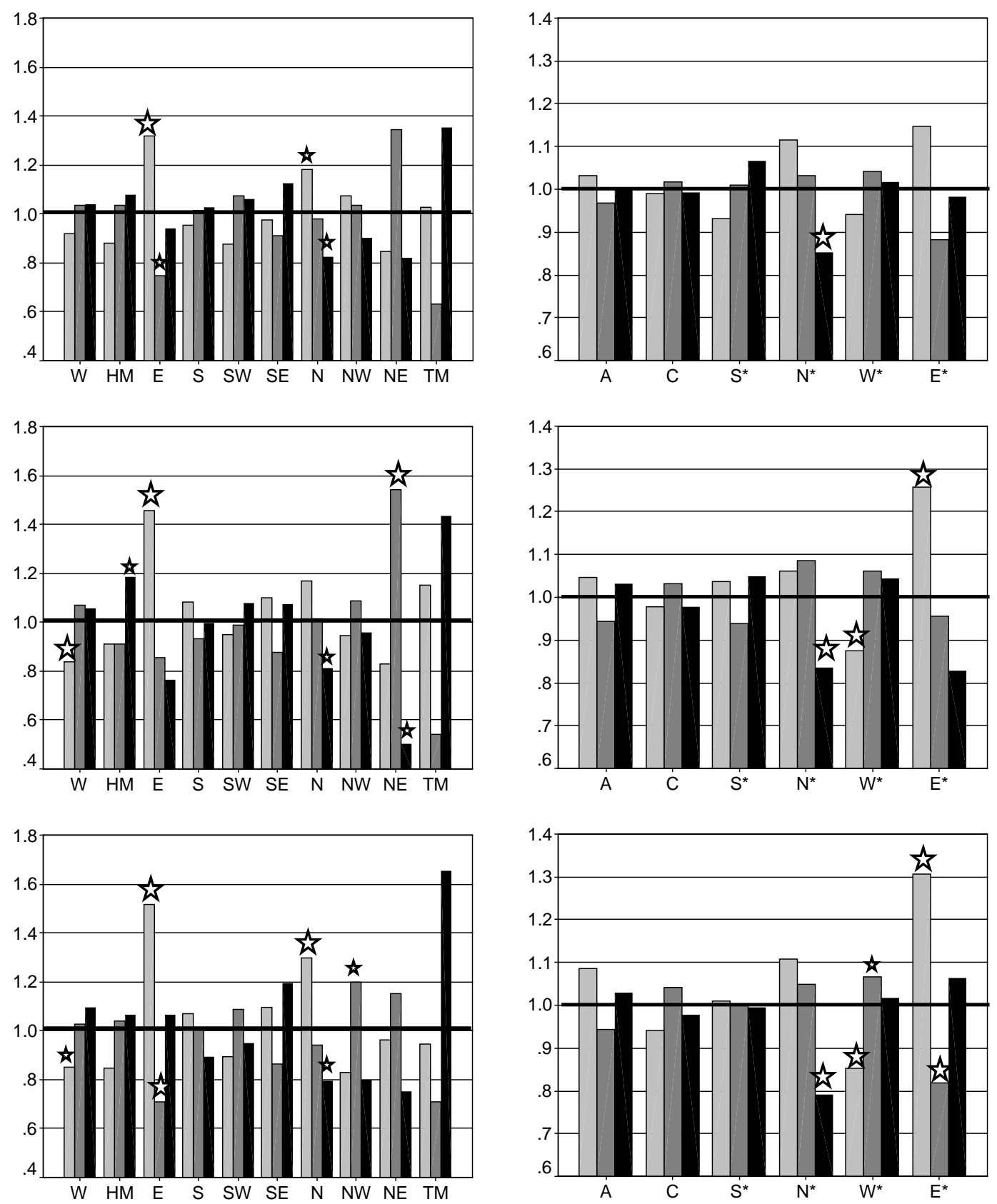

Fig. 2. Ratios of the frequency in a particular solar activity class (thirds in top panels, $\mathrm{min} / \mathrm{max}$ in the middle, quarters in bottom panels) to the long-term mean frequency of major types (left panels) and supertypes (right panels). Each major type/supertype is displayed by one cluster of bars. The bars in each cluster correspond to (from left to right) the low, moderate, and high solar activity. Small (large) star denotes a statistically significant difference from 1.0 at the $10 \%(5 \%)$ level.

a particular solar activity class to the long-term mean frequency for individual major types/supertypes (displayed by clusters of bars). The bars in each cluster correspond to (from left to right) the low, moderate, and high solar activity. The statistically significant values are denoted by a star: a small and large star corresponds to the significance at the $90 \%$ and $95 \%$ level, respectively.
The difference of the ratios from unity and their significance grow with the increasing extremity of the definition of solar minima and maxima. Several features are outstanding in the graphs. First, the westerly types are less frequent in solar minima, which is compensated for by increased frequencies of the easterly types. The main difference in this respect is between the solar minima and the other two classes; 
the differences between the moderate and high activity in the frequency of westerly and easterly types are considerably smaller than the differences between the moderate and low activity. It is worth noting that the easterly major type and supertype are least frequent (except for the min/max stratification) under moderate solar activity, not in solar maxima. A similar, though weaker tendency is observed for the westerly types, which in the $\min / \max$ stratification occur most often under moderate solar activity. Second, the northerly types tend to be more (less) frequent under low (high) solar activity than in their climatological mean: this holds for the northerly supertype $\left(\mathrm{N}^{*}\right)$ and, of the three major types with a north wind component, for the purely northerly one (N) only. This is, however, not compensated for by a change in the southerly, south-westerly, or south-easterly types. The NW and NE major types tend to be most frequent under moderate solar activity. Third, there is a tendency towards the anticyclonic (cyclonic) types to be less (more) frequent under moderate solar activity; this result is consistent among all the three stratifications, although its significance is low, exceeding the marginal level of $80 \%$ for the quarters stratification only. Large changes in the occurrence of the TM major type are statistically insignificant because of its low overall incidence.

The most striking manifestation of the solar effect on the frequency of synoptic types appears for the westerly and easterly supertypes in the quarters stratification. Whereas under the low solar activity, the westerly types are less than twice as frequent as the easterly ones (their frequencies being $39.5 \%$ vs. $20.4 \%$ ), under the moderate solar activity, the frequency of the westerly types is almost four times larger than that for the easterly ones ( $49.5 \%$ vs. $12.8 \%)$.

\section{Discussion and conclusions}

The analysis of H\&B synoptic types under different phases of the 11-year solar cycle confirms and enhances previous results, obtained by various other methodologies, that tropospheric circulation in winter is significantly affected by solar activity. In particular, we notice an increased frequency of easterly types over central Europe under solar minima, together with a corresponding decrease in westerly (zonal) types. This fits well into the picture made up by several previous studies, which all suggest that solar maxima are accompanied by an enhanced zonality in the Euro-Atlantic sector (but not only there): Bochníček and Hejda $(2002,2005)$ in their composite analysis found tropospheric circulation to be more zonal, Kodera $(2002,2003)$ found the North Atlantic Oscillation to be stronger and more spatially extensive, and Huth et al. (2006) found that all the modes of low-frequency variability over Europe and the North Atlantic Ocean become more zonally oriented, while the zonal modes (North Atlantic Oscillation and East Atlantic pattern) become stronger. Similar implications follow from the analysis of the Arctic Os- cillation (or Northern Annular Mode) (Ruzmaikin and Feynman, 2002; Huth et al., 2007). The observation that westerly (and to a lesser extent also easterly) types occur with close frequencies under high and moderate solar activity cannot be easily explained in terms of previous results. The reduced frequency of northerly types in solar maxima is likely to be related to the weakening of the two meridional modes of variability (1st and 2nd Eurasian modes, according to the nomenclature used by Huth et al., 2006) and the change in their shapes from purely meridionally oriented wavetrains towards more zonally oriented "horseshoe-like" patterns. This is also related to the eastward shift of the maximum occurrence of atmospheric blockings over the Euro-Atlantic sector under a high solar activity by about $20^{\circ}$ (Barriopedro et al., 2008). The marginally significant tendency towards cyclonic types being more frequent under moderate solar activity cannot be explained in terms of changes in the modes of atmospheric circulation variability and the reason is unclear.

The amplitude and significance of the solar effects increases with the increasing extremity of the definition of solar minima and maxima. We also note that several effects of the moderate solar activity are not at the "half way" point between the low and high activity, which indicates a likely nonlinearity of the solar effects. Both these findings support our recent results for the variability modes, including the Arctic Oscillation (Huth et al., 2006, 2007).

In summary, we succeeded in showing that (i) synoptic classifications are useful tools for describing solar effects on tropospheric circulation and (ii) different descriptions of tropospheric circulation lead to the same pattern of solar effects, the most striking of which is the suppressed zonality of wintertime circulation in the Euro-Atlantic domain in solar minima. Some results of the present study are not supported by other analyses based on different methodologies; the application of other classifications and studies concentrating on other characteristics of tropospheric circulation than those used here and before (e.g. large-scale circulation regimes, cyclone tracks, cyclone counts) might be helpful for confirming the results as real solar effects or denying them as artifacts of the methodology based on circulation classification.

Acknowledgements. The study was supported by the Grant Agency of the Czech Academy of Sciences, projects A3042401, and during its revision, A300420805. The authors are grateful to the two anonymous reviewers for their encouraging reviews.

Topical Editor F. D' Andrea thanks two anonymous referees for their help in evaluating this paper.

\section{References}

Barriopedro, D., García-Herrera, R., and Huth, R.: Solar modulation of Northern Hemisphere winter blocking, J. Geophys. Res., 113, D14118, doi:10.1029/2008JD009789, 2008.

Benestad, R. E.: Solar Activity and Earth's Climate, SpringerVerlag, Berlin, Heidelberg, New York, 287 pp., 2002. 
Boberg, F. and Lundstedt, H.: Solar wind variations related to fluctuations of the North Atlantic Oscillation, Geophys. Res. Lett., 29, 1718, doi:10.1029/2002GL014903, 2002.

Bochníček, J. and Hejda, P.: Association between extraterrestrial phenomena and weather changes in the Northern Hemisphere in winter, Surv. Geophys., 23, 303-333, 2002.

Bochníček, J. and Hejda, P.: The winter NAO pattern changes in association with solar and geomagnetic activity, J. Atmos. Sol.Terr. Phys., 67, 17-32, 2005.

Brown, G. M. and John, J. I.: Solar cycle influences in tropospheric circulation, J. Atmos. Terr. Phys., 41, 43-52, 1979.

Christoforou, P. and Hameed, S.: Solar cycle and the Pacific 'centers of action', Geophys. Res. Lett., 24, 293-296, 1997.

Gerstengarbe, F.-W., Werner, P. C., and Rüge, U.: Katalog der Grosswetterlagen Europas nach Paul Hess und Helmuth Brezowsky 1881-1998, Deutscher Wetterdienst, Offenbach am Main, 1999.

Huth, R.: An intercomparison of computer-assisted circulation classification methods, Int. J. Climatol., 16, 893-922, 1996.

Huth, R., Pokorná, L., Bochníček, J., and Hejda, P.: Solar cycle effects on modes of low-frequency circulation variability, J. Geophys. Res., 111, D22107, doi:10.1029/2005JD006813, 2006.

Huth, R., Bochníček, J., and Hejda, P.: The 11-year solar cycle affects the intensity and annularity of the Arctic Oscillation, J. Atmos. Sol.-Terr. Phys., 69, 1095-1109, 2007.
Kodera, K.: Solar cycle modulation of the North Atlantic Oscillation: Implication in the spatial structure of the NAO, Geophys. Res. Lett., 29(8), 1218, doi:10.1029/2001GL014557, 2002.

Kodera, K.: Solar influence on the spatial structure of the NAO during the winter 1900-1999, Geophys. Res. Lett., 30, 1175, doi:10.1029/2002GL016584, 2003.

Kuroda, K. and Kodera, K.: Solar cycle modulation of the Southern Annular Mode, Geophys. Res. Lett., 32, L13802, doi:10.1029/2005GL022516, 2005.

Ogi, M., Yamazaki, K., and Tachibana, Y.: Solar cycle modulation of the seasonal linkage of the North Atlantic Oscillation (NAO), Geophys. Res. Lett., 30(22), 2170, doi:10.1029/2003GL018545, 2003.

Ogi, M., Yamazaki, K., and Tachibana, Y.: The summertime annular mode in the Northern Hemisphere and its linkage to the winter mode, J. Geophys. Res., 109, D20114, doi:10.1029/2004JD004514, 2004.

Ruzmaikin, A. and Feynman, J.: Solar influence on a major mode of atmospheric variability, J. Geophys. Res., 107(D14), 4209, doi:10.1029/2001JD001239, 2002.

Tinsley, B. A.: The solar cycle and the QBO influences on the latitude of storm tracks in the North Atlantic, Geophys. Res. Lett., 15, 409-412, 1988. 